\title{
Analysis and Treatment of Abnormal Vibration of a Gas Turbine Generator Set
}

\author{
Hankun Bing ${ }^{1 *}$,Yuzhu Zhao ${ }^{2}$,Zhengfeng $\mathrm{Wu}^{3}$,Le Pang ${ }^{4}$ \\ ${ }^{1}$ ENGINEER,Huadian Electric Power Research Institute, NO. 2Xiyuan 9 Road, Hangzhou Zhejiang Province, 310030, China \\ ${ }^{2}$ SENIOR ENGINEER,Huadian Electric Power Research Institute, NO. 2 Xiyuan 9 Road, Hangzhou Zhejiang Province, 310030, China \\ ${ }^{3}$ SENIOR ENGINEER,Huadian Electric Power Research Institute, NO. 2 Xiyuan 9 Road, Hangzhou Zhejiang Province, 310030, China \\ ${ }^{4}$ ENGINEER,Huadian Electric Power Research Institute, NO. 2 Xiyuan 9 Road, Hangzhou Zhejiang Province, 310030, China
}

\begin{abstract}
In this paper, The turn-to-turn short-circuit fault is accurately judged by the vibration monitoring of a gas turbine generator set. The abnormal conditions in the post-processing process are analyzed and summarized, and the conclusion is verified by the disintegration. The analysis method of abnormal response in the process of dynamic balance of units is determined, which provides a reference for effect evaluation and scheme determination for the on-site dynamic balance treatment of the same type unit.
\end{abstract}

\section{Introduction}

The gas turbine produced by GE company is the type of PG9171E, which is composed of a starting motor with rated power of $1000 \mathrm{KW}$, a 17 -stage axial compressor, a combustion system composed of 14 combustion Chambers and a 3-stage turbine rotor. The axial compressor rotor and turbine rotor are connected by flanges, which have three supporting bearings. The gas turbine generator is air-cooled, three-phase, bipolar, $3000 \mathrm{rpm}, 50 \mathrm{HZ}$ ac, solid cast iron rotor synchronous generator, with $120 \mathrm{MW}$ output power (operating under base load). Exciter is an ac exciter with rotating diode rectifier, and the excitation mode is brushless excitation. The gas turbine shafting support structure is shown in figure 1.1

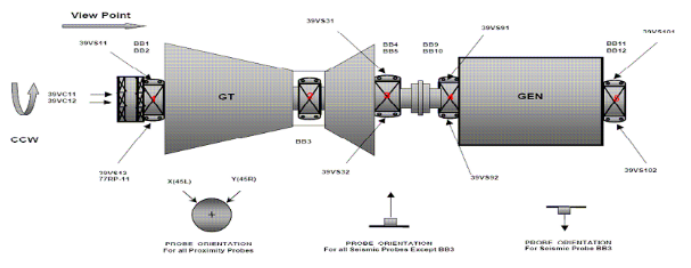

Fig 1.1 Unit shafting structure

\section{Fault overview}

During the operation of the unit, there is a long-term, there is a long-term abnormal increase of the front and rear bearing bush vibrations after the load operation, and the over-critical vibration deterioration due to the frequent start and stop of the unit. According to the historical data of the last two years, the vibration value of \#5 bearing is small when the unit reaches 3000rpm, ranging from 30um to $70 \mathrm{um}$, but there were some differences in the values of each time. The vibration value increases rapidly after loaded and the maximum is $220 \mathrm{um}$. After a few days of stability, it will gradually decline, but the stability values after decline changes greatly, ranging from $40 \mathrm{um}$ to $150 \mathrm{um}$, and then the value will basically stabilize until the downtime.

According to the historical data, the vibration changes of each start, run and stop of engine are basically similar, except for the differences on values. The vibration values of \#4 and \#5 bearings and the variation trend of related operating parameters are shown in figure 2.1 2.3 below.

From the related parameters change trend diagram, the vibration values of \#4 and \#5 bearings are consistent with the rotor current, and there is a certain delay between the change of vibration value and the change of current. After starting up, the vibration value of $5 \mathrm{Y}$ rapidly climbs up with the grid-connection of the unit and the increase of rotor current. After several days of operation, the vibration value gradually drops to a stable value. During the longterm of the later operation period, the vibration value of \#4 and \#5 bearings basically remain stable.

It can be clearly seen from FIG. 2.2 that the vibration value has a relatively consistent correlation with the rotor current, but the only inconsistency is that when the vibration value of $5 \mathrm{Y}$ gradually drops from the maximum value after starting the machine to the stable operating value, the change of vibration value is basically independent of rotor current. Except for the rotor current, there is no obvious consistency between other operating parameters and the vibration value change. During the operation, the factory conducted the variable wind temperature test and found that the vibration change was 
not obvious (the range of wind temperature change was also relatively limited).

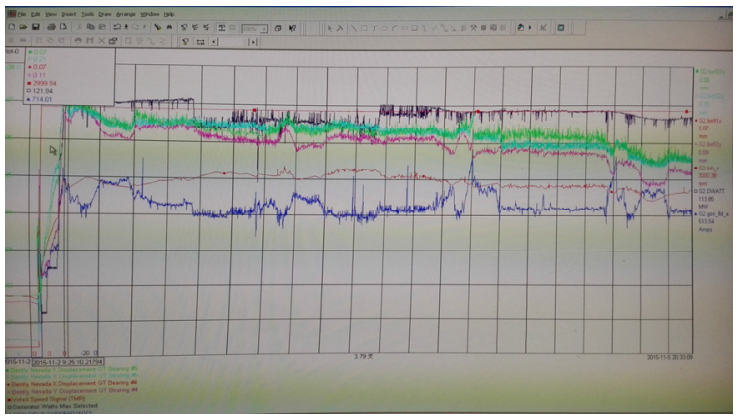

Fig 2.1 Trend diagram after 3000rpm

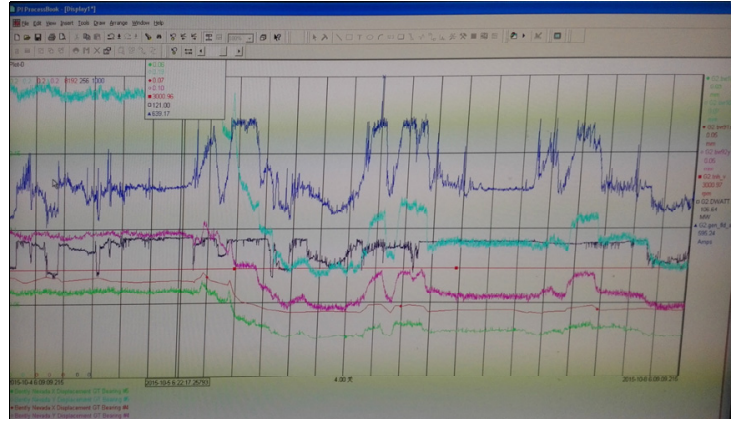

Fig 2.2 Trend chart when falling from maximum value to normal operating value

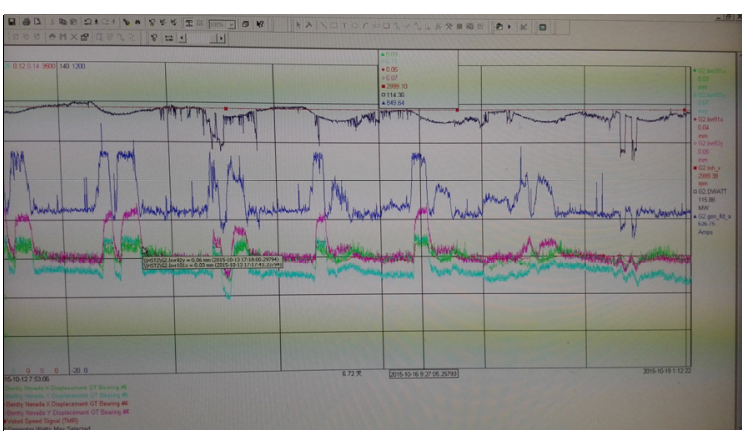

Fig 2.3 Trend pattern with various parameters during normal operation

ROS experiment was carried out by power plant on the generator rotor, and found no abnormalities, but the rotor vibration trend still maintain the original state, The generator rotor was returned to the factory processing during the maintenance period, Rotor winding inter-turn short circuit fault was founded in generator rotor, as shown in figure 2.4. The rotor was returned to the factory for repair, and then returned to the factory for installation. After installation, the machine started to run normally, and the vibration started to climb again after stable operation for 6 months.

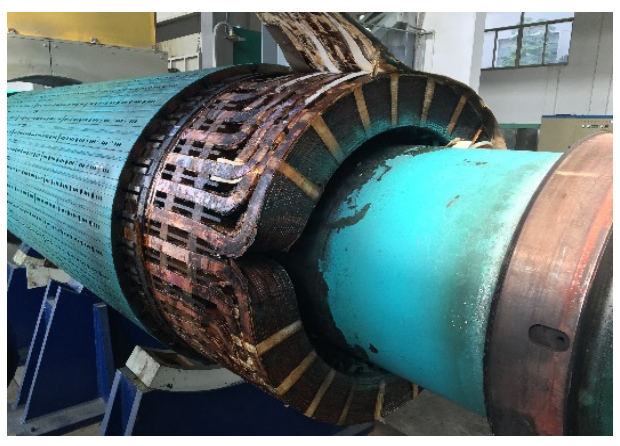

Fig 2.4 Generator disintegration diagram

\section{Vibration monitoring analysis and processing}

Through the summary analysis of the history of the unit, and the monitoring and analysis of the start-up and network connection process of the unit, the data are shown in table 3.1 .

Table 3.1 Generator shaft an $\mathrm{d}$ front axle vibration data

\begin{tabular}{|l|c|c|}
\multicolumn{2}{c}{} & Unit: um $\angle^{\circ}$ \\
\hline$\# 4 \mathrm{X}$ & $67 \angle 12$ & $110 \mathrm{MW}$ \\
\hline$\# 4 \mathrm{Y}$ & $30 \angle 325$ & $53 \angle 213$ \\
\hline$\# 5 \mathrm{X}$ & $102 \angle 196$ & $171 \angle 83$ \\
\hline$\# 5 \mathrm{Y}$ & $50 \angle 271$ & $107 \angle 232$ \\
\hline
\end{tabular}

The weighted test scheme was carried out at 4 watts of the gas turbine and generator opposite wheel and generator, and the response of the weighted test was small after the weighted test. Through analysis and calculation, the weighted test scheme was adjusted at \#4 and \#5 bearings of fan impeller, with 366 grams of weighted test at \#4 bearing and 696 grams of weighted test at $\# 5$ bearing. Vibration of each bearing bush during the starting process after aggravation is shown in table 3.2.

Table 3.2 Shaft vibration data of each bearing in the process of starting after weighting

Unit: um $\angle^{\circ}$

\begin{tabular}{|l|c|c|}
\hline & $3000 \mathrm{rpm}$ & $110 \mathrm{MW}$ \\
\hline$\# 4 \mathrm{X}$ & $56 \angle 60$ & $180 \angle 57$ \\
\hline$\# 4 \mathrm{Y}$ & $32 \angle 312$ & $22 \angle 212$ \\
\hline$\# 5 \mathrm{X}$ & $73 \angle 248$ & $75 \angle 69$ \\
\hline$\# 5 \mathrm{Y}$ & $29 \angle 296$ & $65 \angle 247$ \\
\hline
\end{tabular}

There are obvious differences between the starting data and the theoretical calculation results after aggravation, especially in the $4 \mathrm{X}$ direction, the calculated amplitude and phase of other measuring points are basically consistent with the actual amplitude and phase. Specific to the calculation and analysis of the response to the point dynamic balance of each measurement, there are conflicts in the data, that is, the vibration of $4 \mathrm{X}$ and other 
directions cannot be taken into account, and the aggravation scheme is contradictory. Therefore, this aggravating scheme does not need response adjustment, and the abnormal aggravating response in the $4 \mathrm{X}$ direction should have a great relationship with the bearing bush this week.

In order to analyze the root cause thoroughly, the power plant tested the stiffness of \#4 and \#5 bearings .1-5 is vertical, 6-8 is axial. The test data are shown in table 3.3. By testing the dynamic stiffness of the bearing housing, it is preliminarily judged that there is an abnormality in the \#4 bearing, and the axial vibration is seriously excessive. Through long-term trend tracking, it is found that the trend tends to be stable, and the change of following conformity is not obvious. According to the theoretical calculation results, the vibration amplitude in the $4 \mathrm{X}$ direction will show a downward trend as the unit runs in the later period. The conclusion is verified by tracking the vibration trend. However, in view of the large vibration in $4 \mathrm{X}$ direction, in order to ensure the safe and reliable operation of the unit, the skip protection logic is adjusted. When the power plant took advantage of the shutdown opportunity to check the problem of \#4 bearing bush, from the nose to the tail of the machine, the left excited end of \#4 appeared obvious black gold fall off and wear mark.

Table 3.3 Bearing Stiffness Test Data

Unit: $\operatorname{um} \angle^{\circ}$

\begin{tabular}{|c|c|c|}
\hline $\begin{array}{l}\text { Measuring point } \\
\text { position }\end{array}$ & $\# 4$ bearing & $\# 5$ bearing \\
\hline 1 & $58 \angle 101$ & $40 \angle 281$ \\
\hline 2 & $54 \angle 104$ & $55 \angle 281$ \\
\hline 3 & $53 \angle 101$ & $64 \angle 283$ \\
\hline 4 & $44 \angle 101$ & $62 \angle 286$ \\
\hline 5 & $51 \angle 97$ & $55 \angle 289$ \\
\hline 6 & $298 \angle 266$ & $130 \angle 92$ \\
\hline 7 & $213 \angle 263$ & $94 \angle 89$ \\
\hline 8 & $218 \angle 265$ & $82 \angle 89$ \\
\hline
\end{tabular}

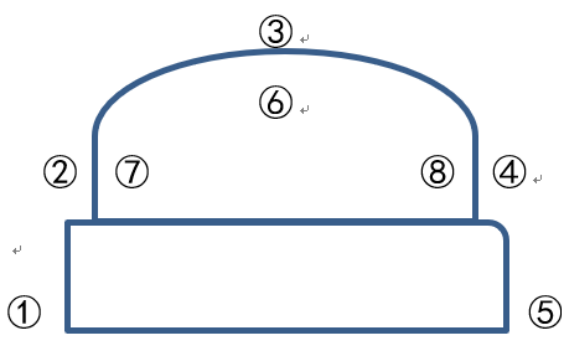

(5).
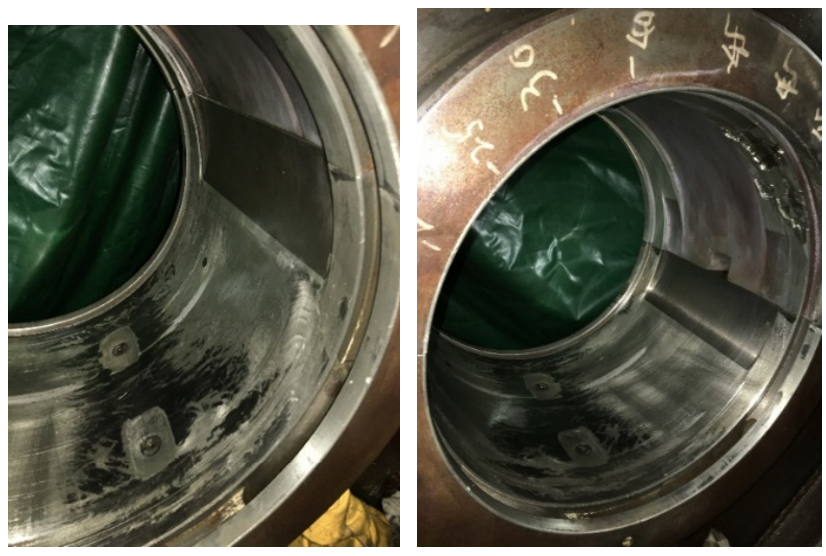

Fig 3.2 \#4 bearing disintegration

\section{Conclusion}

The abnormal increase of generator vibration in a gas turbine power plant is tracked and analyzed, and the possibility of misjudgement in judging the short-circuit between rotor turns in the ROS experiment is illustrated through the field situation. Also in the process of the generator rotor dynamic balance experiment, in the presence of dynamic balance abnormal response, are analyzed, and through the test of bearing stiffness, and dynamic balance response calculation analysis, accurate judgment of dynamic balance processing effect is the cause of the abnormal, the abnormal situation in rotor dynamic balancing process provides referential Suggestions.

\section{References}

1. Gu Huang. Vibration and Balance of Turbine Generator Sets (Second Edition) [M]. Beijing: China Electric Power Press, 1998.

2. Kou Shengli. Vibration and on-site balance of steam turbine generator sets [M]. Beijing: China Electric Power Press, 2007.

3. Shi Weixin. Turbine generator set vibration and accident[M]. China Electric Power Press, 1998

4. Liu shi, Yang qunfa. Vibration analysis and shafting balance of supercritical $600 \mathrm{mw}$ units [J]. Guangdong electric power, 2007,20 (9) : 43-46.

5. Fang jiu-zheng, Yang jian-gang. Vibration analysis and treatment of a gas turbine generator set $[\mathrm{J}]$. Power station system engineering, 2015(6):51-53.

6. Frige, deng yong. Research on vibration of gas turbine generator set during initial starting -- purpose, method, research results of $120 \mathrm{MW}$ generator set [J]. Gas turbine technology, 1995(1):63-68.

Fig 3.1 Schematic diagram of measuring points 